\title{
21 Responding to Coastal Poverty: Should we be Doing Things Differently or Doing Different Things?
}

\author{
J. Campbell, E. Whittingham and P. Townsley \\ IMM Ltd., Innovation Centre, University of Exeter, Exeter, United Kingdom, e-mail: \\ j.campbell-IMM@ex.ac.uk
}

\begin{abstract}
At the interface between land and sea, the coast is arguably one of the most complex and dynamic environments on this planet. Composed of a diversity of interacting natural, socio-cultural, economic and political systems, the coast is in a constant state of change, not only as a result of the constant biophysical forces operating at the coast but also as a result of the significant longer-term changes - population growth, industrial and tourist development, pollution, habitat and biodiversity loss, changes in access rights, markets and technology and the growing reality of climate change - that are increasingly threatening the future sustainability of coastal environments. Although many of these changes occur in other ecosystems, they are particularly concentrated on the coast.

In the past, coastal people, and particularly the coastal poor, have adapted to the intrinsically dynamic nature of the coast, but they now find themselves having to respond and cope within an increasingly competitive environment, in which access to the resources they depend on is becoming more and more restricted and opportunities based on the use of natural resources in general are becoming increasingly limited. For many coastal people, particularly those dependent on natural resources, current changes mean that they must adapt or face increased marginalization and displacement from the coastal resources on which they depend.

This chapter reviews the impact of current changes on the poor in coastal fishing communities, with examples from around the world, and examines existing responses to assist the poor in coping with change on the coast and finding 'alternative livelihoods'. It asserts that current responses supporting the poor to develop their livelihoods have had limited success because of the lack of understanding of who the poor are, the nature of their existing livelihoods and the wider economic, institutional, political and social influences. The use of the sustainable livelihoods approach is discussed as a means of improving our understanding of coastal poverty and linking support for livelihood diversification and enhancement with the livelihoods of the poor, their needs and aspirations, and within the context of local and wider development. Some broad principles to guide more systematic and participatory approaches to interventions are proposed.
\end{abstract}




\section{Background to Coastal Poverty and Coastal Complexity}

In order to respond to poverty on the coast, we first need to understand how coastal complexity interacts with poverty and how that poverty might be defined. Coastal ecosystems are often characterized by their high degree of complexity associated with a number of distinctive features, including their diversity and dynamism, the fugitive nature of some of the resources available, their openaccess nature, the concentration of externalities and people on the coast, and the often hostile nature associated with these features.

\section{Coastal diversity and dynamism}

Coastal diversity reflects the environmental, social, economic and political processes and systems that operate there and the interactions among them, which lead to a high degree of complexity and the potential to generate both opportunities and problems. One of the key aspects of the coast for the poor is the species and ecosystem diversity that provides a wide range of productive opportunities that do not lend themselves to scale economies. The coast is also arguably one of the most dynamic environments on the planet. The daily tidal changes and the seasonal weather patterns are regular factors affecting this dynamism; in addition, the coast is the focus of many sudden weather hazards such as tsunamis, cyclones and tidal floods. It is also subject to the changing patterns of river run-off from the land, which, in places such as Bangladesh, can have a very profound effect on the coast. These effects are worsened when externalities (such as pollution, sedimentation, water abstraction for irrigation and irregular flooding from dams) of upstream industries or countries are concentrated in coastal waters.

\section{Access complexity and dynamism}

Many of the resources that sustain opportunities on the coast for the poor are common- pool resources that the poor are able to exploit because they are open-access or subject to sets of use rights that are poorly defined or largely unenforced. From one point of view, this is an advantage for the poor as it leaves open a 'window of opportunity' to use resources (such as fish, forests, land and wildlife) that are often not available for them in other, non-coastal areas. However, this advantage has a limited lifespan and the poor often find their access to these common-pool resources increasingly restricted for a number of reasons.

Although people on the coast depend on a wide range of natural resources, fish make up an important part of this. Two of the key features that affect fish-dependent livelihoods are the fugitive nature and perishability of fish. Both these factors introduce high levels of risk and uncertainty into the livelihoods of the people who depend upon them, and these risks are compounded by the open-access (and thus potentially competitive) systems that prevail in such areas.

\section{Livelihood diversity}

The dynamic and complex features of the coastal environment represent areas of opportunity for poorer sections of society, as they have no choice but to accept the risks associated with living in marginal coastal areas and the difficult work often involved in exploiting coastal resources. At the same time, because other, better-off groups are unwilling to accept these risks, the coast has often attracted the poor as they may (at least initially) experience less competition for resources there compared with other areas in the hinterland. The wild shrimp seed collection, to satisfy the demand of the growing shrimp aquaculture industry in coastal India and Bangladesh, is a good example of where poorer sections of society have entered difficult and dangerous work in areas prone to cyclones, which are unattractive to the better-off.

The dynamic nature of the coast, the threats it is subject to and the constant changes in the environment faced by the people who live there mean that adaptability 
has always been an essential feature of the livelihoods of coastal people. This is particularly true for the poor and adaptability provides a variety of benefits. The most obvious benefit flows are the food, income and employment that fisheries resources provide. However, benefit flows from coastal resources to the poor are much more complex than simply providing a source of food, income and jobs (see Box 21.1).

\section{Stakeholder diversity and poverty}

In addition to the complexity that surrounds them, the poor make up a diverse group of people with different skills, knowledge, attitudes, traditions, beliefs and histories. Their interactions with the world they inhabit vary between different groups, and often between different households and individuals. Of particular importance in determining how poverty manifests itself amongst different groups are the gender, age and class or caste of those people.

Poverty can be defined in many ways and it is not the role of this chapter to explore this issue in depth. From our research, coastal poor people, like the poor in most other locations, describe their poverty through a diversity of measures rather than solely an absence of money. In a paper titled Exploring the Links, UNEP-IISD (2004) link poverty and well-being to the presence or absence of a range of key determinants:

- adequate nourishment;

- freedom from avoidable disease;

- an environmentally clean and safe shelter;

- adequate and clean drinking water;
- clean air;

- energy for cooking and warmth;

- availability of traditional medicine;

- continuing use of natural elements found in ecosystems for traditional cultural and spiritual practices;

- ability to cope with extreme natural events, including floods, tropical storms and landslides; and

- making sustainable management decisions that respect natural resources and enable the achievement of a sustainable income stream.

It is useful to think of poverty and wellbeing in these complex terms to avoid seeking simple solutions to poverty; this is particularly important on the coast, where the complexity of the ecosystem adds to the complexity of poverty. Even though frameworks for understanding poverty can be developed to high levels of complexity, they do not detract from the fact that the only people who can really define what poverty means are the poor themselves.

Although poverty in some coastal areas is clearly visible (e.g. in coastal Bangladesh), much coastal poverty is hidden from view by the development that is a growing part of much of the coast (especially in urban areas). While some of the poor are able to benefit from these developments, finding paid employment in mechanized fisheries, aquaculture, salt pans or industrial developments along the coast, many are less able to adapt and find themselves excluded from the development processes going on around them. Often they are hidden by the wider coastal development process; they, in effect, become the interstitial poor (Jazairy et al.,

Box 21.1. Benefit flows to reef users

For reef-users, coral reefs provide seasonally stable sources of food, building materials, a medium of exchange, medicines and a source of income and status. It is the coral reef that often gives rise to islands that provide habitats for people and lenses of fresh water for drinking and agriculture. The reef also protects coastal villages from storms and wave action and provides shelter to lagoons and other productive areas, such as sea grasses and mangroves, which in turn provide a reserve of food in all weather conditions. The physical structure of the coral reefs dictates that many activities are performed communally and the traditional linkages between reef resources and the spirit world mean that reefs can be socially and spiritually unifying (Whittingham et al., 2003). 
1992), who live in 'pockets' side-by-side with the better-off and within areas where there may be relatively high levels of development (IMM, 2003a). This characteristic of poverty in coastal areas needs to be distinguished from that found in some inland areas where natural conditions, such as chronic drought, may create a far more generalized condition of relative poverty.

Responding to poverty on the coast requires us to understand not only the nature of poverty found there but also the wider influences that affect the poor. Coasts around the world are characterized by significant changes. The following sections of this chapter review the changes taking place on the coast, the different impacts these changes are having on the coastal poor and current responses to coastal poverty, focusing finally on livelihood enhancement and diversification as a possible way forward.

Evidence is presented from around the world, but focuses mainly on research on the livelihoods of coastal communities in India, Bangladesh, Sri Lanka, Ghana and Cambodia, which was implemented by IMM Ltd. of the UK and its local partners from 2000 to 2004. This work, funded by the UK's Department for International Development (DfID), focused on the livelihoods of poor people on the coast of those countries, how those livelihoods were changing and what might be done to improve them. Although the work covers a broad spectrum of people involved in different coastal livelihood activities, fisheries inevitably form a major part of this work.

\section{Changes on the coast}

In addition to the regular changes that constitute the dynamic nature of the coast, coasts around the world are also undergoing major longer-term changes:

- population growth,

- coastal urbanization and industrialization,

- increasing habitat destruction,

- increasing pollution and sedimentation,

- development of coastal aquaculture,
- increasing access to global markets,

- increasing use of new technologies in resource exploitation,

- declining resource productivity,

- overfishing,

- climate change.

\section{Changing population}

Perhaps one of the most pressing changes on the coast is the rising population. In 1995, it was estimated that almost $40 \%$ of the world's population lived within $100 \mathrm{~km}$ of the coast (Burke et al., 2001), and this number is increasing from both natural population growth and inward migration. In fishing alone, the numbers are impressive: from 1990 to 2000, the number of people directly employed in fisheries and fish farming globally rose from 28 million to 35 million, and $85 \%$ of those people live in Asia (FAO, 2002).

\section{Increasing habitat destruction and pollution}

Increasing coastal populations have led to increasing coastal urbanization with the associated habitat destruction, sewage pollution and increasing freshwater use. Coastal industrialization has added to these pressures, as has port development and coastal tourism. An increasing cause of pollution on the coast is agriculture (Burke et al., 2001), which introduces ever-increasing quantities of agricultural chemicals into coastal waters through run-off. Coastal aquaculture has also impinged upon important coastal habitats, especially through the development of shrimp farms (Pillay, 1992), and in some cases has promoted unsustainable harvesting practices such as that for wild shrimp seed in India and Bangladesh. Deforestation in inland areas has led to increased flooding in coastal areas and to increased sediment loads, resulting in rising siltation of coastal areas affecting inshore habitats and fisheries. As a result of these different forces, critical coastal habitats are under threat, especially mangroves, seagrass areas, coastal wetlands and coral reefs (Burke et al., 2002). In addition, biomass and biodiversity are in decline. 


\section{Increasing competition and unsustainable} exploitation

As more people seek employment in coastal areas and as land areas held by individual households decline, the competition in many parts of the world for traditional employment opportunities on the coast, such as agricultural labour, is increasing. Falling farm employment options push more people to depend on the very common-pool resources (e.g. forests, fisheries, shoreline areas, swamps, mangroves and coral reefs) that the poor have traditionally used to eke out a subsistence living. But many of these resources are declining in productivity as the environmental carrying capacity declines with increasing coastal pollution, habitat destruction, resource depletion and changing water quality and movement patterns. Common-pool resources that historically maintained sustainable levels of communal use are now becoming open-access resources, whose use has become uncontrolled and often unsustainable.

Not only do increasing numbers of people bring with them increasing industrialization and its associated problems, they also increase the harvesting pressure on the available resources. Population pressure, improved access to markets, rising global demand for fish and changes in technology have resulted in many coastal fish resources being at or beyond the point of maximum sustainable yield. Globally, only $25 \%$ of the available major fish stocks are underexploited or moderately exploited, $47 \%$ are fully exploited and $18 \%$ of stocks are overexploited (FAO, 2002).

\section{Changing markets and technology}

New global markets are providing opportunities for selling goods and services far and wide (e.g. Asian vegetables and fish for the European market). However, these often require the adoption of new technologies to ensure uniformity of product or product quality (e.g. woven baskets produced with traditional skills in the village are now being displaced by plastic containers made in factories in cities). Often these technologies are efficient only if they operate with certain economies of scale (e.g. mechanized fishing boats) and this often requires a concentration of capital ownership in the hands of fewer people and, more often than not, in fewer locations. These technologies also often require skills different from those needed in traditional village industries and so new skills must be learned.

\section{Climate change}

Further change is likely in the future as a result of climate change. The Working Group of the Intergovernmental Panel on Climate Change (IPCC, 2001) has identified a series of probable impacts and vulnerabilities of climate change in relation to coastal areas. These areas are expected to become progressively inundated and many small islands are predicted to become partially or wholly submerged. Coastal areas will also be subjected to increased cyclonic weather patterns and increased variability and unpredictability of general weather patterns. Linked to the direct effects of climate change are the likely changes in coastal agricultural activities adjacent to tropical coastal areas. It is projected that these will exhibit a general reduction in crop yields, compounded by declining water availability and a widespread risk of flooding (from both changing precipitation and sea-level rise). In the short term, these climate-induced changes may lead to ever greater dependence on coastal resources (IPCC, 2001).

The ability of human systems to adapt to these changes is highly variable and those with the fewest resources have the least capacity to adapt and are the most vulnerable. Thus, impacts are expected to fall disproportionately on the poor.

\section{Impacts of Change on the Poor}

Changes in coastal areas have had a range of impacts on poor people living on the coast: financial insecurity, increasing employment insecurity and underemployment, loss of rights, exclusion and criminalization of their livelihoods, increased use of child labour 
and increasing gender imbalances. These impacts have not all occurred in all locations but examples of each are widespread. These are outlined below.

\section{Financial insecurity}

Many poor people on the coast are suffering from declining incomes and increasing financial insecurity, mainly as a result of increased competition. Increasing numbers of people are interacting with each other to catch the declining fish stocks: more people are chasing fewer fish and conflicts among people are on the increase. In some cases, declining catches per fisherman is a key factor contributing to declining incomes, such as in the coastal fisheries of Ghana (Ward et al., 2004). People are also competing for available land for agriculture and trees for fuelwood and building materials. The profitability in fishing in many parts of the world is now decreasing and engine failure, gear loss, illness or indebtedness can quickly lead to a loss of fishing assets to moneylenders and middlemen/-women. This is now a major concern of coastal fishermen in Cambodia, where marine catches are under increasing pressure and indebtedness is increasing. In some cases, such as on the east coast of India, the decline in catch rates has been offset by rising market demand, resulting in stable incomes for fishermen, but also in increasing vulnerability as fish stocks become threatened (IMM, 2003a).

For poor processors and traders in India, the declining local supplies of fish and increasing competition have meant that transaction costs have increased, thus reducing their already marginal incomes. This is further worsened where larger-scale outside operators have moved into coastal areas and taken over market access for locally produced products and for credit and microfinance, thus increasing transaction costs and reducing market access for the poor (IMM, 2003a). Likewise, in Cambodia, the market linkages between small-scale producers and processors and urban and export markets are becoming dominated by middlemen, who control prices and ensure their access to fish supplies through credit provision (CFDOIMM, 2005). Although such intermediary activities can be beneficial for the poor in the absence of alternatives, they can also become exploitative where competition is limited, as it is in many parts of Cambodia, thus leading to increased transaction costs (Yim Chea and McKenney, 2003a), increased costs of credit and lowered prices paid to the poor fish suppliers. Additional transaction costs are incurred through the imposition of informal taxes, by corrupt officials, on the movement of products (Yim Chea and McKenney, 2003b) - a highly effective means of extortion in the case of fish, given their high perishability.

\section{Employment insecurity and underemployment}

Globally, the growing demand and competition for fish have increased investment in catching technology, resulting in bigger nets and boats. These in turn require better shore facilities and safer harbours, and so more fish are landed at fewer landing sites. These changes at sea have started to affect people on land. With fewer fish being landed at the smaller landing sites, traditional traders and processors are finding fish harder to come by and employment in the harvesting sector is becoming less secure. In India, increased pressure of people wanting to join fisheries and declining fishing opportunities have led to increased underemployment in the sector (IMM, 2003b). In Cambodia, agricultural labour is also increasing in supply and, with little expansion in demand for this labour, levels of underemployment are high (Sarthi Acharya, 2003). In India, conflicts between small-scale and larger-scale processors and traders in response to changes in fish supply, to access to bigger and fewer landing sites, to changing investment patterns and to changing market access and technology have been identified. The poor are generally least able to adapt and cope with these changes, resulting in increased employment insecurity (IMM, 2003a). Likewise, in Ghana, employment insecurity and underemployment are on the increase among fish processors as 
catches decline or become uncertain and competition between buyers increases (Ward et al., 2004).

\section{Loss of rights, exclusion and criminalized livelihoods}

For many coastal resources, tenure rights are unclear or not defined (Luttrell, 2001). Where conflicts over access rights to common-pool resources have increased with the growth of competition in coastal areas, the poor are often the least able to defend their livelihoods or to establish tenure rights that are supported by the legal system and effectively documented. At times, this is because the poor are simply unaware of the rights that they may have and are unfamiliar with the mechanisms through which they can assert their rights. On other occasions, the rights of the poor are actively suppressed in favour of those who have better access to the prevailing legal and political system, are able to understand the language used and can influence the attribution of exclusive rights in their favour.

For migrants, who are commonly among the poorest groups to be found in coastal areas, this situation is particularly marked as they often lack local language skills, are politically weak and have no linkages with local systems of patronage or support, and may often be regarded with suspicion by a large proportion of local people (Box 21.2). This often translates into a systematic trampling of even the most basic rights of some of these marginal migrant groups. Following the devastating cyclone in Orissa, India, where the legal status of people affected their access to rehabilitation support (IMM, 2001), this situation became particularly marked.

The fact that many coastal resources are open-access - the very feature that has enabled the poor to use them - may also lead to their alienation from the poor. While the poor may, initially, be the only group willing to engage in the exploitation of 'difficult' resources such as mangrove swamps, the open sea or coastal areas, once the economic incentives and technology make it viable for others to exploit those resources as well, the poor often find themselves in competition with a wider group of people who have a comparative advantage over them. So, fish resources, previously the exclusive preserve of artisanal fishers, come to be increasingly monopolized by those using more efficient mechanized trawlers, leading to the progressive exclusion of artisanal fishers from the use of the resource. The resulting conflicts between technology levels, such as those off the coast of Kerala in India, are well documented (Kurien, 1992).

In addition, coastal swamps and mangroves used by the poor for a variety of livelihood activities have been progressively converted for aquaculture, agriculture or industrial development, again removing these resources from the common pool and from the uses of the poorer sections of coastal society. With the growth of aquaculture in Andhra Pradesh in India, for instance, traditional occupations such as fish drying and fishing with beach-seines, which required large open areas, are confined to increasingly congested areas. Even fish landings that took place all along the coast are now concentrated in smaller areas (IMM, 2003a; IMM-ICM, 2003). The poor often find that coastal development operates faster than they can cope with. In Vietnam, for example, some poorer farmers have been forced to sell their rice fields to people who are able to make the needed investments for shrimp culture (Luttrell, 2001).

The expansion of coastal tourism in some areas has also led to conflicts with local people; efforts to exclude fishermen from conservation areas have also created tension in some areas. For many of the poor, changes in policies or management plans favouring conservation priorities have left parts of their livelihoods on the wrong side of the law. With few options available to many coastal poor people, they tend to remain in those criminalized livelihoods and absorb the additional risk that this incurs.

For example, some marine protected areas in India, focused on biodiversity conservation and tourism, are off-limits for local fishery activities. In the Gulf of Mannar Marine Biosphere Reserve, access to and 
Box 21.2. The lost rights of coastal migrants

In India, the shoe-dhoni fishermen of Andhra Pradesh have traditionally migrated to areas along the coast from their base in the Godavari delta. Although many of the shoe-dhoni people have been migrating for decades, they have few rights in the areas where they spend much of the year and they are losing them in their home area. They have never been allowed by local people to build even temporary homes on the land as there is a general fear that this will lead to attempts to acquire other rights to local resources that are already fiercely contested among local inhabitants. So, the shoe-dhoni people simply live on their boats when they migrate (IMM, 2003b).

exploitation of shallow reef and sea-grass areas surrounding the 21 coralline islands in the Gulf are prohibited and the Wildlife Protection Act (1972) prohibits the collection of many reef species. For the majority of poor reef stakeholders living along the coast of the Gulf of Mannar, these restrictions place severe restraints on their livelihoods. With no viable alternatives, poor reef stakeholders continue to access prohibited reef resources at great risk and increasing transaction costs (Rengasamy et al., 2003). In Cambodia, the decline in the availability of coastal fuelwood relative to the demand is causing more people to harvest forest resources from protected areas (CFDO-IMM, 2005). Many people have few alternatives to continuing with the now illegal harvests and to facing the consequences: fines or bribes.

Criminalized livelihoods are also associated with the declining returns from fishing globally, which are encouraging an increase in fishing effort to compensate and in many places the use of illegal fishing gear. In India and Bangladesh, the harvesting of wild shrimp seed has become illegal, either directly or through changes in gear restrictions (IMM, 2003a). In Ghana, declining catches are forcing many fishermen to use light fishing, which is illegal (Ward et al., 2004). This has, in effect, criminalized the livelihoods of many thousands of coastal poor people, but they have few alternatives but to continue with these fishing practices.

\section{Using child labour}

The use of child labour in coastal communities is a common strategy for many of the poorer households coping with declining income and increasing vulnerability. Children on the coast of Ghana, for example, were found to play an important role in different postharvest fishery activities, providing labour in fishing, processing and trading (Ward et al., 2004). In many cases, child labour takes place in resident communities; however, in some cases it was also reported that children from coastal households migrate to work. In Ghana, coastal children are found working in the inland Lake Volta fishery. Although illegal and discouraged, child labour is often a key strategy for the poorest households.

In Cambodia, in a survey implemented in Krong Preah Sihanouk, 1678 children were found working in three fishing areas, involved in a diversity of work on fishing boats, repairing nets, peeling shrimp, removing crab meat from the shell, freezing fish and transporting fish (NIS, 2001). Although often a key livelihood strategy among the poor, child labour is often seen as a problem as it can have the double effect of depriving the children of their education and limiting their future chances of getting out of poverty through better employment. However, for many poor people, the pressures of today far outweigh the benefits of tomorrow.

\section{Gender imbalances}

Change on the coast is also affecting the balance in the roles played by men and women both within the household and in wider society.

Men and women are able to respond to development opportunities in different ways in different cultural and religious situations. Opportunities that benefit men may disad- 
vantage women (and vice versa) and the benefit balance of the household may not be improved overall. For example, in India, the increased landings of fish at larger landing sites and the reduction in landings at local village markets have been easier for men to access as they are more able to travel longer distances from their homes (IMM 2003b). By contrast, women have often found it more difficult to access landings that are distant from their home villages and face greater problems in dealing with the more competitive environment often found at larger fishing harbours. In addition, increased mechanization in fisheries has displaced men from fishing activities in some areas and more are now entering the fish trade, and thus increasing competition with traditional women traders and processors (IMM, 2003a). Likewise, in Cambodia, both occupational and geographic mobility of women are less than for men, thus affecting their ability to take up new employment opportunities (Sarthi Acharya et al., 2003).

Closely linked to this are the different ways in which migration affects men and women. Although seasonal migration has been a traditional response to fugitive fish stocks in some coastal communities, fishermen and labourers, in as diverse a range of places such as Ghana, India and Cambodia, are changing their migration patterns in search of a better life. Migration is now taking on new dimensions: people (especially men) are moving for longer periods, they often set up semi-permanent second homes and they are exploring new areas to migrate to where they do not have traditional social safety nets. In many cases, women are left behind to become, de facto, heads of households. On the east coast of India, part or all of some fishing communities migrated along the coast to either avoid bad weather or to follow mobile fish resources to areas where they were more abundant. More recently, fishers have been migrating to the west coast for part of the year, but they return home during the period of the southwest monsoon when fishing in the Arabian Sea is much more difficult (IMM, 2003a). In Sri Lanka, seasonal migrations from the western to the eastern and northern coasts were severely affected by the security situation, which effectively removed the associated fishing grounds from access (IMM, 2003a). In some cases in the region, such seasonal migrations are met more and more by hostility from the local population as competition for resources increases (IMM, 2003a).

The rapid changes that characterize many coastal areas create opportunities, but people's ability to respond to those opportunities is variable. The coastal poor are often the least able to adapt to, or to cope with, these changes. They have limited access to new technologies, to the skills, knowledge, confidence or education to use them, or to the finances to purchase them. Nor do they have the time to invest in their development or the financial reserves to take the risks associated with them. They also characteristically lack the networks to access new knowledge, skills, technologies, finances and markets. In many instances, the poor, who are least able to adapt, face increased marginalization and displacement. Many development agencies on the coast have the remit to respond to these changes and their responses, along with those of the poor themselves, are discussed in the next section.

\section{Responses to Coastal Poverty}

It is recognized that, barring major philosophical and policy shifts, the situation of degradation of ecosystems and poverty within and between countries is likely to get worse (UNEP-IISD, 2004). This situation requires urgent action on the part of all stakeholders, from the poor to the international community. The poor have actively been trying to escape poverty, or at least cope with an increasingly bad situation, by adapting their livelihoods. Governments and aid agencies have also attempted to address these issues through development programmes and the targeting of poverty reduction strategies. Conservation efforts have tried to limit the damage to key ecosystems, fisheries management has attempted to move towards more sustainable use of resources and integrated coastal management initiatives have tried to link develop- 
ment and environmental concerns specific to the coast. More recent interventions have tried to balance poverty and conservation through pro-poor conservation initiatives. There have been successes and failures in all of these.

\section{The responses of the poor}

The poor do not sit idly by and passively accept the changes that are occurring on the coast. Often they cope with the situation and adapt to the changes; sometimes they diversify their income-earning activities to both supplement their income and reduce risk, or even move into new alternatives (Barrett et al., 2001; Luttrell, 2001). Aquaculture has sometimes been adopted as an alternative to fishing or to agriculture (Luttrell, 2001), but turning fishers into fish farmers is not always easy (World Bank, 2004).

A frequent response to the pressures on the coast, particularly for men, is to migrate to new areas where their current skills will be needed. As discussed above, they often change their income/employment sources (e.g. farmers becoming fishermen, fishermen becoming traders). These may seem to be minor changes but they involve many adaptations and adjustments that relate to household roles, transportation, social networking, credit arrangements, market access and knowledge. Coping often involves accepting, at least in the short term, reduced livelihood expectations and probably increased risks, for example, through illegal fishing. It may also involve dipping into any savings they may have or selling capital, such as jewellery, cattle or boats. In India and Ghana, in some cases reduced returns from fishing have resulted in poor fishers giving up highinput technology and reverting to low-cost traditional technologies, such as sail power (IMM, 2003b; Ward et al., 2004). This may mean that they move from selling the produce from their own small area of land or from their fishing boat to selling their labour on other people's land or boats. If children are at school, they may have to be moved into the workforce to contribute to household income (IMM, 2003a).

\section{General development programmes}

Although the poor are often unable to take up all the opportunities or respond to or cope with the threats that the changes on the coast generate, many have benefited from a diversity of general development programmes that have been aimed at poverty reduction and wider rural community development. Improved access to low-cost housing, improved local education, better water supplies, more accessible health services, group organization and an increased say in decision-making through local government reforms (such as the Panchyati Raj institutions in India) have had a marked effect on the lives of at least some of the poor. In other areas, the poor may be too poor to benefit from such wider development initiatives when these developments still involve costs (such as fees to access education and health services) that are unacceptable to the very poor.

\section{Targeted responses}

There have also been targeted responses to poverty on the coast. NGOs in particular have been very effective at working in villages to provide credit and training to allow the poor to invest in new opportunities or to expand existing ones. In Bangladesh, the NGO sector is very active at the community level in building support networks that provide opportunities and create safety nets for the poor; for example, the Grameen Motsho Foundation has rented land from the government to help a large number of poor people participate in aquaculture. However, the extent to which many of the NGO efforts have allowed the poor to leave poverty, rather than to be more secure within poverty, has yet to be adequately demonstrated on a large scale.

The creation of targeted delivery mechanisms alone has frequently failed to address the underlying causes and features of poverty that often make it extremely difficult for the poor to take advantage of services that are available. Obstacles for the poor include a lack of awareness of services and 
programmes available to help them, lack of confidence in dealing with bureaucracies and officials, and the assumption that they are 'too poor' to be eligible for assistance (IMM, 2003a). More recently, efforts by both government and NGOs have attempted to pay more attention to the capacity of the poor to take up services and programmes aimed at benefiting them, especially through self-help groups for micro-finance, for example, in coastal communities in coastal Bangladesh (D. Kumar, Bangladesh, 2003, personal communication).

\section{Fisheries management}

Fisheries management has been an important strategy for ensuring the sustainable use of resources in recent years, but the cases where this has been really successful are notable for their scarcity. Centrally planned and implemented fisheries management systems have failed for a variety of reasons, not least of which relate to the uncontrollable access arrangements of most fisheries, the cost of enforcement over many fishing units over many small landing sites, the lack of involvement of fishers in decision-making processes, conflicts between policy objectives and the gap between policies and action (World Bank, 2004).

Greater emphasis is now being placed on the greater involvement of fishing communities and fishers themselves in the management of fishing efforts through comanagement systems. ${ }^{1}$ The evolution of such measures is still in its early stages. Much work has been done on experimenting with different management arrangements for comanagement, for example, for inland fisheries in Bangladesh (Department of Fisheries, 1999a,b; Middendorp et al., 1999), from which lessons are being learned.

Co-management has the potential to play a significant role in future coastal development strategies, particularly if it embraces fisheries as a social policy instrument, rather than just as a contributor to national productivity. As a social policy instrument, it has the potential, through targeting, to address the socio-economic needs of communities that are highly dependent on fisheries for their survival, to address the needs of communities that are regarded as being very poor and to start to address wider environmental concerns.

\section{Coastal Management}

Attempts have been made to address the complex and conflicting demands on the coast through a range of integrated coastal area management (ICAM) approaches. These have a diversity of names such as integrated coastal management (ICM), integrated coastal zone management (ICZM) and coast conservation (CC), but they are broadly similar in approach. Under such approaches, the actual management of resource use tends to remain within relevant sector ministries such as fisheries, forestry, agriculture, etc., whereas ICAM implementation has tended to focus on the horizontal coordination function that links different ministries together and integrates policies and policy implementation.

These ICAM initiatives have generally started from a resource management perspective, working on the basis that, if resources are well managed and conflicts over resource use controlled, development is more likely to be sustainable. This management focus was not always intended to be the outcome of the ICAM process but was rather to be the strategy by which coastal development was to be enabled. The keynote address to the ASEAN/US CRM (coastal resource management) conference on managing ASEAN's coastal resources for sustainable development in 1990 mentioned that 'Government leaders ... should not view CRM as 'anti-development' or purely a 'conservationist' stance, but rather as a viable strategy for improving the quality of life of

\footnotetext{
1 The term 'co-management' here is used to describe all fishery management arrangements where the community/fishers and the government share aspects of the management regime, including so-called community management measures.
} 
the people whom they have vowed to serve, through increased food supply, alternative livelihoods, employment and investment opportunities and long-term solutions to multiple-use resource conflicts' (Macaraig, 1991). However, globally, the application of ICAM to address the needs of wider coastal development has proved less successful than was hoped. Olsen and Toby (1997) said, '... that despite a flowering of initiative and support for the idea of ICM, both investments and successes are puny compared to the forces worldwide causing coastal transformation. Worse yet, ICM projects, particularly in developing nations, are proceeding as isolated efforts with little or no communication between one project and another'. In an analysis of a number of ICAM projects in East Africa, Moffat et al. (1998) said, 'Projects focusing on biodiversity protection but neglecting local development are often only successful in the short term'.

Part of the problem is that the management strategies to achieve wider development policies on the coast have often become more dominant than the policies themselves and the development goal has sometimes been left behind. As Clark (1996) says of ICM, 'In its management mode, [it] assesses the environment and socio-economic impacts of specific development projects and recommends changes necessary to conserve resources and protect biodiversity'. In measuring the success of ICAM projects, Matuszeski (2001) said, 'The ultimate measures of success must be the recovery and sustained health of coastal resources themselves'. These statements reflect a shift in policy away from wider sustainable coastal development inclusive of people towards resource management as an objective in itself.

This is not to say that ICAM in its various forms is not the way forward. ICAM has an important role to play in coastal development, but we must not assume that the sound management of resources is synonymous with creating opportunities for the poor. Management, unless it is specifically targeted at helping the poor, is likely to remove opportunities from them.

\section{Conservation of coastal resources}

Much emphasis has been placed on conserving coastal resources to ensure their availability to future generations. However, in attempts to conserve the resources that the poor depend on, the good intentions of government and conservation NGOs have sometimes resulted in the poor being inadvertently excluded from the benefits of such conservation. The poor often depend on coastal resources in complex ways that are difficult to see or understand. Some rely on aquatic resources continuously, others only periodically when land-based opportunities are few (e.g. in the agricultural low season); some have alternatives that they can fall back on; others depend on aquatic resources for absolute survival; some depend on a wide range of benefit flows from the resources while others depend on only a few (Whittingham et al., 2003). It is difficult to understand and accommodate these different levels and forms of dependence in conservation measures (Box 21.3).

Box 21.3. Marine protected areas

Marine protected areas (MPAs) are one of the key tools in the coastal management toolbox and they can be extremely useful for conserving coastal resources. However, unless they are applied with great care, they can also become major obstacles to the livelihoods of the poor by excluding them from key benefit flows from the protected resources, especially when dependence is critical and alternatives are few. For example, in the Lakshadweep Islands of India, mollusc collection from the coral reef is now banned. Mollusc collecting has traditionally been a major livelihood occupation of some of the poorest elderly women on the islands who have few options for other forms of income (Hoon, 2003). 


\section{Pro-poor conservation}

The intrinsic links between poverty and the environment have been well known, discussed and debated for many years, and the need to respond to both simultaneously is stated in a diversity of global policy initiatives such as Agenda 21, the Convention on Biological Diversity (CBD), the International Coral Reef Initiative's Call for Action, the World Summit on Sustainable Development (WSSD), the Durban Accord and the Millennium Development Goals (MDGs). The practice, however, has slipped considerably behind the policy and very little attention, until recently, has been paid to implementing pro-poor conservation/management measures in meaningful ways. Reed (2001) wrote, '.. during the 10 years since the World Conference on Environment and Development was held in Rio de Janeiro, very little attention has been given to the intimate relationship between rural poverty and the environment'.

More recently, pro-poor conservation/ management has begun to emerge as a practical strategy. Part of this process has been the recognition that poverty is not just a lack of income and a move to a much more multidimensional view of poverty (UNEP-IISD, 2004). Linked to this is a growing recognition that responses to the poverty-environment nexus need to be multidimensional, and to step outside of the traditional conservation approach. It is also increasingly recognized that the relationship between poverty and the environment is not a simple downward spiral and that population increase does not necessarily lead to environmental degradation (UNDP-EC, 1999). There is also a growing recognition of the value of poor people's perceptions of their own development, resulting in a greater inclusion of participatory approaches in management measures, although these can range greatly from information extraction to being fully empowering (Campbell and Salagrama, 2001).

\section{Alternative livelihoods}

For many concerned with coastal management, alternative livelihoods are seen as the way to help and encourage people dependent on coastal resources to move away from unsustainable harvesting practices (e.g. the World Bank-funded COREMAP Project in Indonesia). The International Coral Reef Initiative, in its 'Renewed Call to Action', highlighted the importance of alternative sources of income as essential to the management of the coral reef resource (ICRI, 1999). As the poor are often the most dependent on the common-pool resources of the coast, it is often they who fall within the framework of the push for alternative livelihoods. In fact, 'alternative livelihoods' has become the new mantra for many in the coastal management world. This is often seen as the panacea for coastal problems, especially when linked to the restricted access rights associated with marine protected areas.

However, the complexity of initiating and sustaining diversified livelihoods is often underestimated. Those involved in coastal conservation and management are often from technical ministries, such as environment, fisheries, coastal engineering or forestry, and they do not always have either the remit or the skills to engage in developing these alternatives. In many cases, the suggestion alone that alternative livelihoods need to be found for those considered to be degrading the resources is as far as the response goes. In part, this is because alternative livelihoods require interventions across many overlapping and adjacent administrative jurisdictions, and as such they remain outside the remit of any particular one. In effect, they become the stepchild of government, donor and NGO efforts (Haggblade et al., 2002).

Initiatives aiming at the promotion of alternatives have suffered from several common failings. Particularly where the search for alternative livelihoods has been driven by the desire to reduce the exploitation of natural resources, the needs and priorities of the poor themselves are often given less importance than the desire of the concerned agencies to protect particular resources or areas. Efforts to propose new or alternative activities have often concentrated on menus of 'new ideas' generated by outsiders rather than on encouraging the poor themselves to 
properly analyse their strengths, weaknesses, opportunities and threats and come to decisions regarding the options available to them based on that analysis, and on positive perceptions of where they wish to see their lives going. Many of these have been short-term interventions that have underestimated the time required to create capacity among the poor to take up new activities. Often efforts have just increased the diversity in the livelihood portfolio with none of the intended reduction in resource exploitation. In other cases, the alternative options offered are taken up more easily and more quickly by the wealthier members of the community, or taken up and abandoned, for example, in the case of agricultural opportunities for coral reef miners in Sri Lanka (Perera, 2003).

\section{Livelihood Enhancement and Diversification - the Way Forward?}

As can be seen from the discussion above, diverse problems face the poor on the coast but there is little agreement about how these problems should be addressed. Various initiatives, ranging from conservation of coastal resources to their sustainable and equitable use, are being tried, with varying degrees of success. The development of alternative income-generating opportunities (AIGOs) is now emerging as an important strategy, but success has been limited to date.

\section{Where are we now?}

From this discussion, two key points start to emerge. First, that the way we currently manage the coastal resource base is neither sustainable nor, in most cases, very equitable. Second, that harvesting from the existing natural resource base cannot provide employment and income for the ever- increasing coastal population at levels that will raise or keep those people out of poverty. The implication of this is that displacement from coastal resource dependency will increasingly have to become a key strategy in addressing sustainability, poverty and conflicts on the coast.

To put these concerns more positively, we need to manage current exploitation more effectively so that it is both sustainable and more equitable, and increase non-primary industry opportunities for people, either to reduce their dependency on the coastal resource base or to leave (or, for the young, not enter) primary industries and move into secondary and tertiary industries. In other words, coastal people need to do things differently and do different things. This can be represented on a spectrum, as shown in Fig. 21.1.

However, for those who do have the remit, resources and skills, the process of generating viable and sustainable alternatives is still not easy or straightforward. Understanding rural and coastal livelihoods and how and why rural people generally, and coastal people specifically, diversify their income-generating activities themselves is key to developing effective strategies to support this process. However, this is poorly understood and attempts to assist this process have tended to be based on only limited understanding of the factors and forces that are needed to ensure success. The few studies that exist suggest that the factors influencing successful livelihood enhancement and diversification are complex and that these include both endogenous and exogenous factors. Endogenous factors include the sense of identity that people have, their perceptions of risk, their ethnic origins, their culture and religion, their gender (see Knudsen and Halvorsen, 1997, for a discussion on the role of gender), their age and their education and wealth. Exogenous factors include the market for diversified

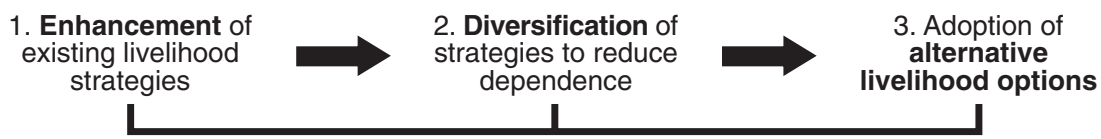

Fig. 21.1. Three broad approaches to improving coastal livelihoods. 
goods and services (especially its size and seasonality), infrastructure, communications, finance availability, policies, legislation and patronage. Neither of these lists is exhaustive.

To develop sustainable livelihoods, the influence of these two groups of factors needs to be balanced; however, past development efforts have tended to focus on improving the environment for economic growth through improved exogenous factors, that is, creating opportunities for growth. As discussed earlier, all too often the poor are the least able to take up these opportunities, which are instead taken up by the more educated, wealthier and better connected members of rural communities. This can lead to a development exclusion paradox, in which coastal development and livelihood diversification are generally taking place, but the poor fail to benefit from these opportunities, falling in the gaps to become, as discussed above, the interstitial poor. Providing safety nets to compensate for those people left behind in the development process is one approach to addressing this. However, a more sustainable and effective route would be to better understand and address those endogenous factors that can enable the poor to compete more effectively in the marketplace for viable livelihood change.

\section{Developing a way forward}

As discussed above, the promotion of alternative livelihoods within coastal management efforts has often focused on external and short-term initiatives, which frequently fail to reach the poor. A key element affecting the likelihood of success seems to be the degree to which the complexity of the livelihoods of the poor is well understood and incorporated into the design of the intervention. Addressing livelihood diversification and enhancement must also address the changing nature of the coast, that is not so much a periodic phenomenon as an ongoing process. Today's viable alternative is unlikely to be sustainable unless it also incorporates the capacity to evolve with the changes around it.
The Sustainable Livelihoods Approach (SLA) offers a way of addressing coastal livelihood complexity and may provide an entry point to supporting coastal poverty and livelihood change. The SLA is a way of understanding the capacities and strengths of the poor and setting the objectives of development so that those objectives are based on what the poor already have and can do, and are responsive to the external policy, institutional and vulnerability context (see Carney, 1998, for an outline). The SLA has been in existence, and has been evolving, since the 1980s. It is used by several development agencies such as UNDP, IFAD, FAO, OXFAM, CARE and DfID (Ashley and Carney, 1999). It evolved from a wide array of participatory and other grass-roots approaches to working with the rural poor and in many ways it brings together past methods and best practice into a consolidated approach that is both comprehensive and fairly easy to understand and use. What is new about the SLA is that it embraces the complexity of rural livelihoods from the perspective of the poor. It takes the poor as the centre of the development process because they are the ones most in need of support and it provides a mechanism for enhancing empowerment of the poor (see Fig. 21.2).

\section{Focusing on the approach rather than on the alternative income activities}

Livelihood-based approaches have already begun to be adopted in systematically identifying and promoting alternative incomes. The details of these alternatives are specific to the location and groups concerned and are less relevant to this wider discussion than the broad approaches used. For example, an intervention in southern Africa, having recognized the complexity of the situation, carried out a detailed analysis of the livelihoods of the women concerned, then presented the results to the community and discussed ideas for an intervention. The strategies were then discussed with extension agents and, when interventions were agreed upon, the women themselves worked with the extension agents to prepare a feasibility study of 


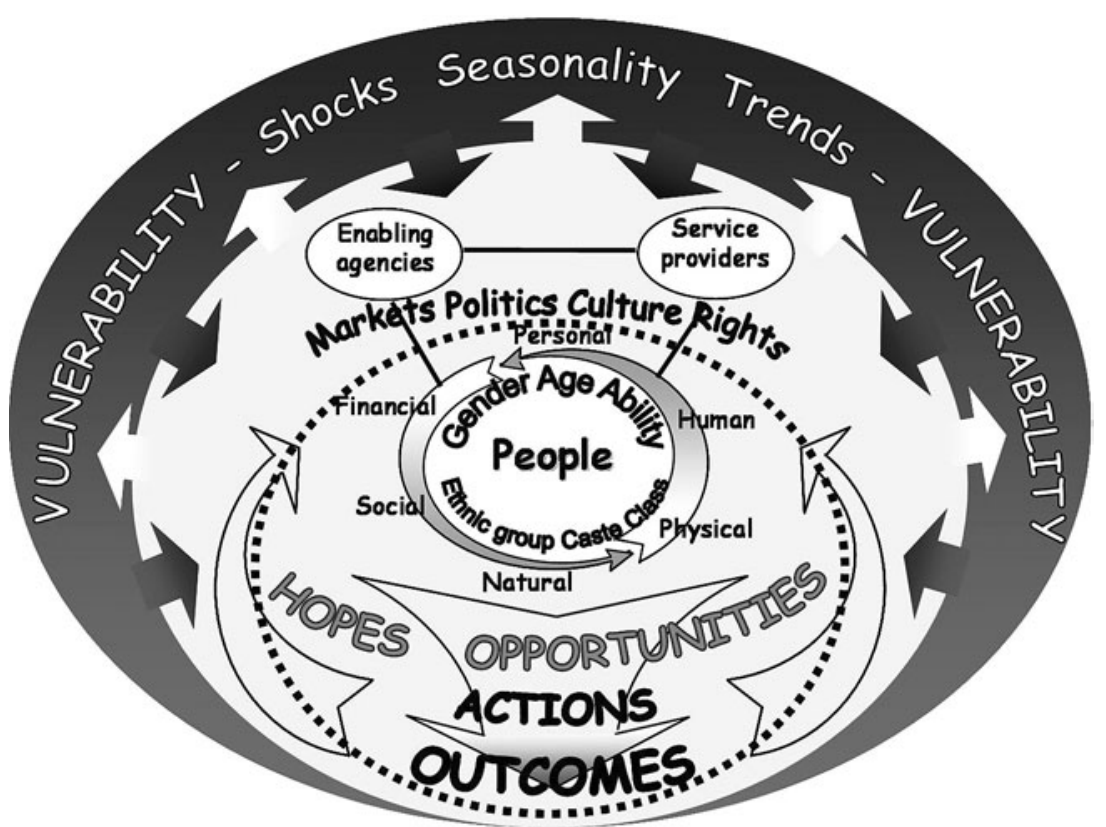

Endogenous factors are represented by all those factors inside the dashed circle. Exogenous factors are represented by all those factors outside the dashed circle.

Fig. 21.2. A framework for understanding and responding to livelihoods of the poor. (From Julian Hamilton-Peach and Philip Townsley at www.itad.org/s/a/framework/index.htm)

the proposal (Due, 1991). Ellis (2000) uses the Sustainable Livelihoods Approach as a framework for understanding livelihoods, livelihood diversification and the factors affecting it; Allison and Ellis (2001) apply SLA to understanding the diverse livelihood strategies of fishers confronted with changing fishery resources. Dasgupta et al. (2004) have also used the SLA to systematically analyse the diversification of rural livelihoods in India. The research undertaken by IMM and referred to in this chapter has been implemented largely through livelihood approaches, providing new insights into the livelihoods of the coastal poor and the relationships between the poor, the surrounding coastal resources and the policy context in which they operate.

The application of livelihood approaches to coastal poverty and livelihood enhancement and diversification is based on several key principles:

- They should build on the strengths of the poor.
- They should relate to the needs and aspirations of the poor.

- They should be developed in participatory ways.

- They should make use of multidisciplinary approaches.

- They must be viable and sustainable (from economic, institutional, social and cultural perspectives).

- They should be appropriate for the number of people concerned.

- They should have acceptable (to the poor) levels of risk.

- They should not increase vulnerability.

- They should be in harmony with existing household livelihood strategies.

- They should complement the strategies of other people in the community.

- They should conform with national policies and legislation.

- They should enhance the independence of the poor.

- They should ensure the rights of the poor. 
- They should ideally enhance the innovative capacity, vision and adaptability of the poor.

Approaches should build on the strengths of the poor and be implemented in participatory ways to accommodate the aspirations and needs of different stakeholder groups. The focus should be on a range of strategies, which include: (i) enhancing existing uses of aquatic resources to make them more sustainable and more equitable; (ii) diversifying people's livelihoods to reduce their dependence on natural resources; and (iii) developing alternatives, especially for the next generation about to join the coastal work force. Such livelihood change also needs to be accompanied by greater emphasis on building the capacity of people to respond to future change so that they will continue to innovate and maintain the viability of their livelihoods.

Such efforts will require multidisciplinary approaches that require networks that bridge the gaps between administrations and NGOs and allow them to work together to bring their different skills, knowledge and experience to the issues. Above all, coastal livelihood change needs to be mainstreamed over a long period of time rather than being a short-term activity or an afterthought to conservation or management initiatives. And, livelihood change for the poor needs to be at the centre of the mainstreaming process if the poor are to stand a chance of benefiting.

\section{Conclusions}

The situation on the coast is complex and that complexity has created opportunities for the poor. However, those opportunities are decreasing as coastal populations rise, access to global markets increases, technology becomes more advanced and greater investment is made in the coast. Efforts to conserve coastal resources or to improve the effectiveness of management regimes have often led to further marginalization of the poor and increasing conflicts. Even where AIGOs have been generated, the poor have not always benefited from them.

There is clearly a need to improve the way resource use is managed to overcome problems of both sustainability and equity. Co-management systems, better integration across sectors and agencies on the coast to achieve wider coastal development and propoor conservation all have roles to play in enhancing the way people interact with the coast. However, in the medium to long term, more people will have to be encouraged to move out of livelihoods that depend on primary production on the coast and be encouraged and supported to engage in secondary and tertiary industries. Efforts to address this issue have already started but success has been limited. The 'menu approach' to livelihood change (where specific livelihood options that are supposed to work in all situations are selected from a global list of coastal alternatives) has not proved very successful and addressing single issues as obstacles to diversification is an oversimplification.

There are no simple solutions - we need to incorporate all the different factors that affect the ability of people to identify, take up and sustain livelihood changes. These factors need to be understood and responded to systematically in ways that recognize and respond to the complexities of poor people's lives rather than using predetermined strategies. Sustainable Livelihoods Approaches are one way of doing this.

\section{References}

Allison, E.H. and Ellis, F. (2001) The livelihoods approach and management of small-scale fisheries. Marine Policy 25, 377-388.

Ashley, C. and Carney, D. (1999) Sustainable Livelihoods: Lessons from Early Experience. DFID, London.

Barrett, C.B., Rearden, T. and Web, P. (2001) Nonfarm income diversification and household livelihood strategies in rural Africa: concepts, dynamics, and policy implications. Food Policy 26, 315-331.

Burke, L., Kura, Y., Kassem, K., Revenga, C., Spalding, M.D. and McAllister, D. (2001) Pilot Analysis of Global Ecosystems: Coastal Ecosystems. World Resources Institute, Washington, DC. 
Burke, L., Selig, E. and Spalding, M.D. (2002) Reefs at Risk in South-east Asia. World Resources Institute, Washington, DC, pp. 1-72.

Campbell, J. and Salagrama, V. (2001) New approaches to participation in fisheries research. FAO Fisheries Circular No. 965, 56.

Carney, D. (1998) Sustainable rural livelihoods: what contribution can we make? Papers presented at the Department for International Development's Natural Resources Adviser's Conference, 1998. DFID, London.

CFDO-IMM (2005) The Cambodia Post-harvest Fisheries Overview. Department of Fisheries, Phnom Penh, Cambodia.

Clark, J.R. (1996) Coastal Zone Management Handbook. CRC Press, Inc., Boca Raton, Florida.

Dasgupta, N., Klei, U., Marter, A. and Wandschneider, T. (2004) India: policy initiatives for strengthening rural economic development: case studies from Madhya Pradesh and Orissa, India. NRI report No. 2770, Natural Resources Institute, Kent, UK.

Department of Fisheries, Bangladesh (1999a) Papers presented at the National Workshop on Community Based Fisheries Management and Future Strategies for Inland Fisheries in Bangladesh. DOF, Dhaka, Bangladesh.

Department of Fisheries, Bangladesh (1999b) National Workshop on Community Based Fisheries Management and Future Strategies for Inland Fisheries in Bangladesh: Recommendations for Future Strategies for Inland Fisheries and Workshop Summary. DOF, Dhaka, Bangladesh.

Due, J.M. (1991) Experience with income generating activities for Southern African women. Savings and Development, Vol. 1, XV.

Ellis, F. (2000) Rural Livelihoods and Diversity in Developing Countries. Oxford University Press, UK.

FAO (2002) The State of World Fisheries and Aquaculture. FAO Information Division, FAO, Rome.

Haggblade, S., Hazell, P. and Reardon, T. (2002) Strategies for stimulating poverty-alleviating growth in the rural nonfarm economy in developing countries. International Food Policy Research Institute and the World Bank, Washington, DC.

Hoon, V. (2003) A case study from Lakshadweep. In: Whittingham, E., Campbell, J. and Townsley, P. (eds) Poverty and Reefs: Volume 2 Case Studies. For DFID, IMM and IOC-UNESCO by UNESCO, Paris, pp. 187-226.

ICRI (1999) Renewed Call to Action: International Coral Reef Initiative 1998. Great Barrier Reef Marine Park Authority, Townsville, Australia.

IMM (2001) Learning Lessons from the Cyclone: A Study of DFID's Support for Post-Cyclone Livelihoods Rehabilitation in Orissa, India. IMM Ltd., Exeter, UK.

IMM (2003a) Sustainable Coastal Livelihoods: Policy and Coastal Poverty in the Western Bay of Bengal: Main Report. An output from the Sustainable Coastal Livelihoods project funded by DFID's Policy Research Programme. IMM Ltd., Exeter, UK.

IMM (2003b) Major Trends in the Utilisation of Fish in India: Poverty-Policy Considerations. Output of Project R7799: Changing Fish Utilisation and Its Impact on Poverty in India, funded by DFID's Post-harvest Fisheries Research Programme. IMM Ltd., Exeter, UK.

IMM-ICM (2003) Changing Fish Utilisation and Its Impact on Poverty in Andhra Pradesh: A Scoping Study. Output of Project R7799: Changing Fish Utilisation and Its Impact on Poverty in India, funded by DFID's Post-harvest Fisheries Research Programme. IMM Ltd., Exeter, UK.

IPCC (2001) Climate Change 2001: Impacts, Adaptation and Vulnerability - Summary for Policymakers. A report of Working Group II of the Intergovernmental Panel on Climate Change (17).

Jazairy, I., Alamgir, M. and Panuccio, T. (1992) The State of Rural Poverty: an Inquiry into Its Causes and Consequences. Published for the International Fund for Agricultural Development, IT Publications, London.

Knudsen, A.J. and Halvorsen, K. (1997) Income-generating programmes in Pakistan and Malawi: a comparative review. Journal of Refugee Studies 10(4), 462-475.

Kurien, J. (1992) Ruining the commons and responses of the commoners: coastal overfishing and fishworkers' actions in Kerala State, India. In: Gai, D. and Vivian, J. (eds) Grassroots Environmental Action: People's Participation in Sustainable Development. Routledge, London.

Luttrell, C. (2001) Institutional change and natural resource use in coastal Vietnam. GeoJournal 54, 529-540.

Macaraig, C. (1991) Sustainable development of coastal resources: a challenge and a choice. In: Thia-Eng, C. and Scura, L.F. (eds) Managing ASEAN's Coastal Resources for Sustainable Development: Roles of Policymakers, Scientists, Donors, Media and Communities. Association of South-east Asian 
Nations/United States Coastal Resources Management Project Conference Proceedings 6, Manila, Philippines.

Matuszeski, W. (2001) Coastal management: in search of success. Intercoast Network, International Newsletter of Coastal Management No. 40, 2001. Coastal Resources Center, University of Rhode Island, Kingston, Rhode Island.

Middendorp, H.A.J., Thompson, P.M. and Pomeroy, R.S. (1999) Sustainable Inland Fisheries Management in Bangladesh. ICLARM, Danida and the Ford Foundation. ICLARM, Manila, Philippines.

Moffat, D.M., Ngoile, M.N., Linden, O. and Francis, J. (1998) The reality of the stomach: coastal management at the local level in Eastern Africa. Ambio 27, 590-598.

NIS (2001) Cambodia Child Labour Survey 2001. National Institute of Statistics, Ministry of Planning, Phnom Penh, Cambodia.

Olsen, S. and Toby, J. (1997) Avoiding an ICM Nightmare. Intercoast Network No. 29, Fall 1997, Rhode Island.

Perera, N. (2003) Alternative Livelihoods Through Income Diversification: An Option for Sustainable Coral Reef and Associated Ecosystem Management in Sri Lanka. South Asia Cooperative Environment Programme in collaboration with Coral Reef Degradation in the Indian Ocean (CORDIO) Programme, Colombo, Sri Lanka.

Pillay, T. (1992) Aquaculture and the Environment. Fishing News Books, Oxford, UK.

Reed, D. (2001) Poverty is not a number, the environment is not a butterfly. WWF 'Viewpoints on Poverty and the Environment'. WWF, Washington, DC.

Rengasamy, S., Devavaram, J., Prasad, R. and Arunodaya, E. (2003) A case study from the Gulf of Mannar. In: Whittingham, E., Campbell, J. and Townsley, P. (eds) Poverty and Reefs: Volume 2 Case Studies. For DFID, IMM and IOC-UNESCO by UNESCO, Paris, pp. 113-146.

Sarthi Acharya (2003) Off-farm and non-farm jobs in SEATEs and Thailand: rationale and synthesis of country studies. In: Development Analysis Network. Off-Farm and Non-Farm Employment in Southeast Asian Transitional Economies and Thailand. Cambodia Development Resource Institute, Phnom Penh, Cambodia.

Sarthi Acharya, Kim Sedara, Chap Sotharith and Meach Yady (2003) Off-farm and non-farm activities and employment in Cambodia. In: Development Analysis Network. Off-Farm and Non-Farm Employment in South-east Asian Transitional Economies and Thailand. Cambodia Development Resource Institute, Phnom Penh, Cambodia.

UNDP-EC (1999) Attacking Poverty While Improving the Environment: Practical Recommendations. UNDP, New York.

UNEP-IISD (2004) Exploring the Links: Human Well-Being, Poverty and Ecosystem Services. IISD, Winnipeg, Canada.

Ward, A.R., Bortey, A., Whittingham, E., Braimah, L.I., Ashong, K. and Wadzah, N. (2004) Poverty and post-harvest fishery livelihoods in Ghana. Output from the Post-Harvest Fisheries Research Programme Project R8111. IMM Ltd., Exeter, UK.

Whittingham, E., Campbell, J. and Townsley, P. (2003) Poverty and Reefs. Vols 1 and 2. DFID-IMMIOC/UNESCO, Paris.

World Bank (2004) Saving Fish and Fishers: towards Sustainable and Equitable Governance of the Global Fishing Sector. Agriculture and Rural Development Department, Washington, DC.

Yim, Chea and McKenney, B. (2003a) Domestic fish trade: a case study of fish marketing from the Great Lake to Phnom Penh. Cambodia Development Resource Institute Working Paper No. 29. Phnom Penh, Cambodia.

Yim, Chea and McKenney, B. (2003b) Fish exports from the great lake to Thailand: an analysis of trade constraints, governance, and the climate for growth. Cambodia Development Resource Institute Working Paper No. 27. Phnom Penh, Cambodia. 